\title{
Complications in cardiac surgery: An analysis of factors contributing to sternal dehiscence in patients who underwent surgery between 2010 and 2014 and a comparison with the 1990-2009 cohort
}

\author{
Mariusz J. Listewnik ${ }^{A-F}$, Tomasz Jędrzejczak ${ }^{A, E-F}$, Krzysztof Majer $^{B, C}$, Aleksandra Szylińska ${ }^{B, C}$, \\ Anna Mikołajczyk ${ }^{B, C}$, Krzysztof Mokrzycki ${ }^{E, F}$, Elżbieta Górka ${ }^{B}$, Mirosław Brykczyński ${ }^{E}$ \\ Department of Cardiac Surgery, Pomeranian Medical University in Szczecin, Poland \\ A - research concept and design; $B$ - collection and/or assembly of data; $C$ - data analysis and interpretation; \\ $\mathrm{D}$ - writing the article; $\mathrm{E}$ - critical revision of the article; $\mathrm{F}$ - final approval of the article
}

Address for correspondence

Mariusz J. Listewnik

E-mail: sindbaad@poczta.onet.pl

Funding sources

None declared

Conflict of interest

None declared

Received on November 5, 2017

Reviewed on January 14, 2018

Accepted on August 9, 2018

Published online on April 15, 2019

Cite as

Listewnik MJ, Jędrzejczak T, Majer K, et al. Complications in cardiac surgery: An analysis of factors contributing to sternal dehiscence in patients who underwent surgery between 2010 and 2014 and a comparison with the 1990-2009 cohort. Adv Clin Exp Med. 2019;28(7):913-922.

doi:10.17219/acem/94154

DOI

10.17219/acem/94154

Copyright

Copyright by Author(s)

This is an article distributed under the terms of the

Creative Commons Attribution Non-Commercial License

(http://creativecommons.org/licenses/by-nc-nd/4.0/)

\section{Abstract}

Background. Sternal dehiscence is a serious postoperative complication of cardiac surgery observed in $0.2-5 \%$ of procedures performed by median sternotomy.

Objectives. Assessment of factors, including the method of sternum closure, which may affect the incidence of this complication.

Material and methods. A total of 5,152 consecutive patients undergoing surgery with median sternotomy access in the Cardiac Surgery Department of the Pomeranian Medical University between 2010 and 2014 were included in the study. The analysis centered on cases of sternal dehiscence, which occurred in 45 patients (0.9\%).

Results. Factors such as age $(p<0.05)$, body mass $(p<0.005)$ and coronary artery bypass surgery (CABG) $(p<0.005)$ were found to be significant risk factors. Diabetes and chronic obstructive pulmonary disease (COPD) also had an impact on an increased risk of sternal dehiscence $(p<0.006$ and $p<0.015)$. However, the differences were only significant in the whole study group. Apart from $C A B G$, the type of operation did not affect the incidence of dehiscence. Logistic regression analysis found independent risk factors for the development of sternal dehiscence: body mass index (BMI) (odds ratio (OR): 2.1; $p<0.019$ ), diabetes (OR: 2.4; $p<0.004)$, COPD (OR: $2.7 ; p<0.016$ ), and redo procedure (OR: 3.0; $p<0.014)$. There were no significant differences in postoperative mortality between these groups $-6.7 \%$ in the group with sternal dehiscence and $3.9 \%$ in the group without dehiscence.

Conclusions. Introducing a more durable sternum stabilization method with $8+$ loops helped to improve conditions for bone union and reduced the risk of dehiscence. Therefore, we suggest that centers which still use 6-loop sternal closure should consider shifting to a stronger technique.

Key words: risk factors, cardiac surgery, median sternotomy 


\section{Introduction}

Sternal dehiscence after a cardiac surgery procedure is still a very serious complication observed in $0.06-12.50 \%$ of patients and associated with an increase in perioperative mortality. ${ }^{1-4}$ In a previous publication we described 298 cases $(2.1 \%)$ of sternal dehiscence after 14,117 procedures performed between 1990 and 2009. ${ }^{5}$ The previous analysis was performed due to modification of the postoperative sternum closure technique, which happened at the beginning of 2010. Instead of 6 single wire loops we started to use a closure with 8-12 single loops, depending on the quality of osseous tissue of the sternum, but mostly depending on the body weight of the patient with a simple assumption of 1 loop for every $10 \mathrm{~kg}$ of body weight and no fewer than 8 loops per patient.

After 5 years from the introduction of the new sternal closure technique, we decided to examine whether it had an impact on the incidence of postoperative sternum dehiscence. Naturally we are aware of the fact that the results of both papers are not comparable due to the retrospective nature of the studies they describe. The scope of the procedures, demographic characteristics of the assessed group, environmental factors and methods of treatment have changed. The patients are older (therefore diabetes occurs more often) and have a higher body mass index (BMI), which means they are more susceptible to sternal dehiscence. Although we have a specific standard of preventive antibiotic therapy, the drug resistance of some bacteria has reached almost $100 \%$. The previously predominating Gram-positive bacteria were replaced by Gram-positive and opportunistic strains that were not a risk factor in the past. ${ }^{6}$ However, there are some positive changes.

One of the new techniques that increase the effectiveness of sternum closure is the application of cement, similar to the one used in dentistry. ${ }^{7}$ Yet it seems that the most significant breakthrough has been made in the techniques employed for dealing with complications. The introduction of vacuum-assisted closure (VAC), a still undervalued modality in our opinion, seems to be a very important element that shapes the treatment of surgical wound healing complications such as sternal dehiscence. ${ }^{6}$

The study aimed to analyze factors which may have an influence on the incidence of sternal dehiscence in patients undergoing surgery in our center during the period of 5 years from the introduction of a new sternal stabilization method.

We compared groups with sternal dehiscence and without this condition by performing an analysis of population factors, concomitant diseases and perioperative data. The study was based on data retrieved from the computerized Departmental Database that contains data gathered from our institution since 1990.

The statistical analysis was performed using STATISTICA v. 10 (StatSoft, Inc., Tulsa, USA). The $\chi^{2}$ test, t-test, Mann-Whitney $U$ test, logistic regression analysis, and discriminant analysis were used in the study. The results have been presented as percentage and mean values \pm standard deviation (SD). The threshold for statistical significance was $\mathrm{p}<0.05$.

\section{Material and methods}

The retrospective study included consecutive patients who underwent surgery with sternotomy access in the period from 1/01/2010 to 31/12/2014. Sternal dehiscence requiring surgical intervention was found in $45(0.87 \%)$ patients out of 5,152 operations with median sternotomy access.

Fifty-four patients were not included, as they had valve replacement procedures (in 1 case also a graft of ascending aorta prosthesis) with minimal access by partial upper sternotomy and the operative technique precluded full sternal dehiscence.

The technique of primary sternum closure was identical to that used in the years 1990-2009 apart from increasing the number of loops to 8+. As to secondary closures, if the dehiscence was mainly due to loosening of wire loops, we tried tightening them by pulling and twisting the wire. If a full dehiscence occurred, the standard, Robitsek or Martinez closure technique was used. In a few cases we additionally used bone cement to stabilize the closure.

The introduction of VAC as a method of choice whenever sternal wound infection was suspected was a significant improvement. Fluid collection or purulent discharge from the wound, skin dehiscence, a fistula, or a suspicion of hematoma in the wound were indications for partial or complete opening of the wound and applying VAC therapy. During the period of the study, we used systems of several companies, predominantly Hartmann (Paul Hartmann AG, Heidenheim, Germany), KCI (Kinetic Concepts, Inc., San Antonio, USA) and Smith\&Nephew (Smith \& Nephew, Inc., London, UK). In VAC therapy, the wound is drained using a controlled level of negative pressure. This eliminates the necessity of frequent dressing changes (a few times a day when using a conventional approach). Vacuum assisted closure dressings are changed every 3 to 4 days with a simultaneous lavage or debridement of the wound and culture. Two subsequent negative results of culture were indications for closing the wound. Due to a controlled level of negative pressure, the VAC dressing causes a local vasodilation, increases the temperature of neighboring tissues and is conducive to the migration of leucocytes as well as removing wound discharge. By restricting contact with the infected wound secretion (the VAC foam is covered with a self-adhesive, microporous membrane) the risk of environmental contamination and transfer of bacteria to the staff or other patients is reduced. The use of VAC therapy obviously entails an increase in treatment cost. Nevertheless, a comparison of all expenses involved in treatment with VAC and conventional therapy shows that the former is much more cost-efficient. ${ }^{6}$ 
The entire study group was composed of 5,152 patients aged 17-90 years (mean $64.7 \pm 9.28$ ). There were 3,646 men (age: $63.7 \pm 9.04$ years) and 1,506 women (age: $67.1 \pm 9.56$ years). The mean BMI was $28.7 \pm 4.44$ in the whole study group, $28.0 \pm 4.07$ in men and $28.6 \pm 5.23$ in women. In spite of a very similar result, the differences were statistically significant. There were no statistically significant sex-specific differences in normal body weight and obesity. The majority of underweight patients were men, and as far as overweight, and severe, morbid and super obesity were concerned, the majority were women.

Due to the rising average age of patients undergoing surgery, there were more patients with diabetes and chronic obstructive pulmonary disease (COPD) in comparison to the previous study period. Diabetes was reported in 1,649 (32.0\%) patients, significantly more often in women than in men. The COPD was reported in 327 (6.3\%) patients, without any sex-specific differences. The most prevalent disease was hypertension; 3,528 (68.4\%) of the patients were treated for this condition, women again forming the majority. The same trend was observed for coexisting chronic renal failure, which was diagnosed in 409 (7.9\%) patients. In contrast, myocardial infarction was found significantly more often in men. Overall there were 2,188 (42.4\%) patients with this diagnosis. Furthermore, we also analyzed the impact of an additional factor defined as movement limitations. Such condition may occur as a consequence of many diseases such as: stroke with significant paresis, advanced degenerative changes in facet joints and lower limb joints, multiple sclerosis, morbid and super obesity, amputation in the area of lower limbs, as well as elephantiasis and edema of lower limbs in the course of post-thrombotic syndrome. Movement limitations may heighten the risk of sternal dehiscence due to increased stress on the shoulder girdle during recovery (when getting up from bed and walking). Movement limitations were found in 369 (7.2\%) of the patients undergoing surgery, women representing a significant majority.

Another indicator of the functional status of the heart that we investigated was ejection fraction (EF). Mean EF value was around $50 \%$ in the entire group; a significantly higher result was reported in women.

Mean cardiopulmonary bypass (CPB) duration, which may be treated as an approximate indicator of the severity of surgery, was $65.2 \mathrm{~min}$ in the entire group, significantly longer in women.

The mean value of the perioperative mortality risk index Euroscore Logistic (ESL) was 6.8\%. Women had a significantly higher mortality risk (9.3\% vs $6.4 \%)$. This was reflected in actual perioperative mortality, exactly half the predicted value (3.9\%), but also with a significant majority of deaths in female patients (5.5\% vs 3.3\%). The data is presented in Table 1.

In the reported interval, most of the operations $(4,701)$ were conducted in $\mathrm{CPB}$. The most frequently performed procedures were: coronary artery bypass grafts (CABG
- 2,964), procedures for heart valves (590), aortic aneurysms (287), and combinations of CABG with 2 other types of procedures (822). Among procedures performed without cardiopulmonary bypass (CPB) (451), off-pump coronary artery bypass surgery (OPCAB) formed the largest group (424). The annual number of patients who had surgery with median sternotomy access was between 997 and 1,093 (mean 1,030 \pm 38.7 ) in the reported period. Table 2 summarizes the types of operations performed. Due to a large number of combinations, we only included the main types of procedures.

Out of 4,222 CABG operations, 3,798 (90.0\%) were performed using the standard approach in cardiopulmonary bypass, whereas 454 (10.0\%) were off-pump procedures. The dominating model of operation was a single bypass graft from the left internal thoracic artery (LITA) to the branch of the left anterior descending artery (LAD) and a bypass graft from the saphenous vein, usually sequential, to other coronary vessels. Apart from LITA, the right internal thoracic artery (RITA) and radial artery from the non-dominant hand, i.e. mostly left, was used.

Using at least one thoracic artery as a bypass conduit to the LAD belongs to the so-called golden standard. We use it in our center whenever it is possible and indicated. We avoid using ITAs in exceptional situations, especially when: 1 . the patient undergoes emergency surgery, is being resuscitated, or presents with low output syndrome and harvesting the ITA could delay revascularization and pose a risk of hypoperfusion in the site of anastomosis due to contraction of the ITA under the influence of high doses of catecholamines often used in such situations; 2. if a difference in blood pressure of more than $30 \mathrm{~mm} \mathrm{Hg}$ to the detriment of the planned side of ITA harvesting was detected or stenosis of the ITA was diagnosed angiographically; 3 . when LAD is not included in planned revascularization; 4. during reoperation, when one ITA was previously used or damaged and the other one is not suitable for harvesting; 5 . when the harvested ITA cannot be grafted (atherosclerotic lesions, dissection or other type of damage inflicted during harvesting) or when an area of the patient's chest including the ITA was previously injured or irradiated.

Of the 3,798 patients included in the CABG group, a single ITA (SITA) was used in 3,247 patients. The ITA was harvested but was unsuitable for grafting in 32 patients and replaced by a venous bypass graft. This subset of patients was included in the SITA group. To this group we also added 1 patient from outside the CABG group whose ITA was harvested but could not be grafted because the LAD had severe atherosclerotic lesions and was too narrow.

Both ITAs were used in 329 patients. Five patients, who had 2 arteries harvested but only 1 (4) or none (1) suitable for grafting, were added to this group. For reasons mentioned above, no bypass grafts with ITAs were performed in 148 patients. They had 1-4 venous bypass grafts and in 2 cases also a graft from the radial artery. 
Table 1. Pre- and perioperative data of whole patient group treated by sternotomy in years 2010-2014

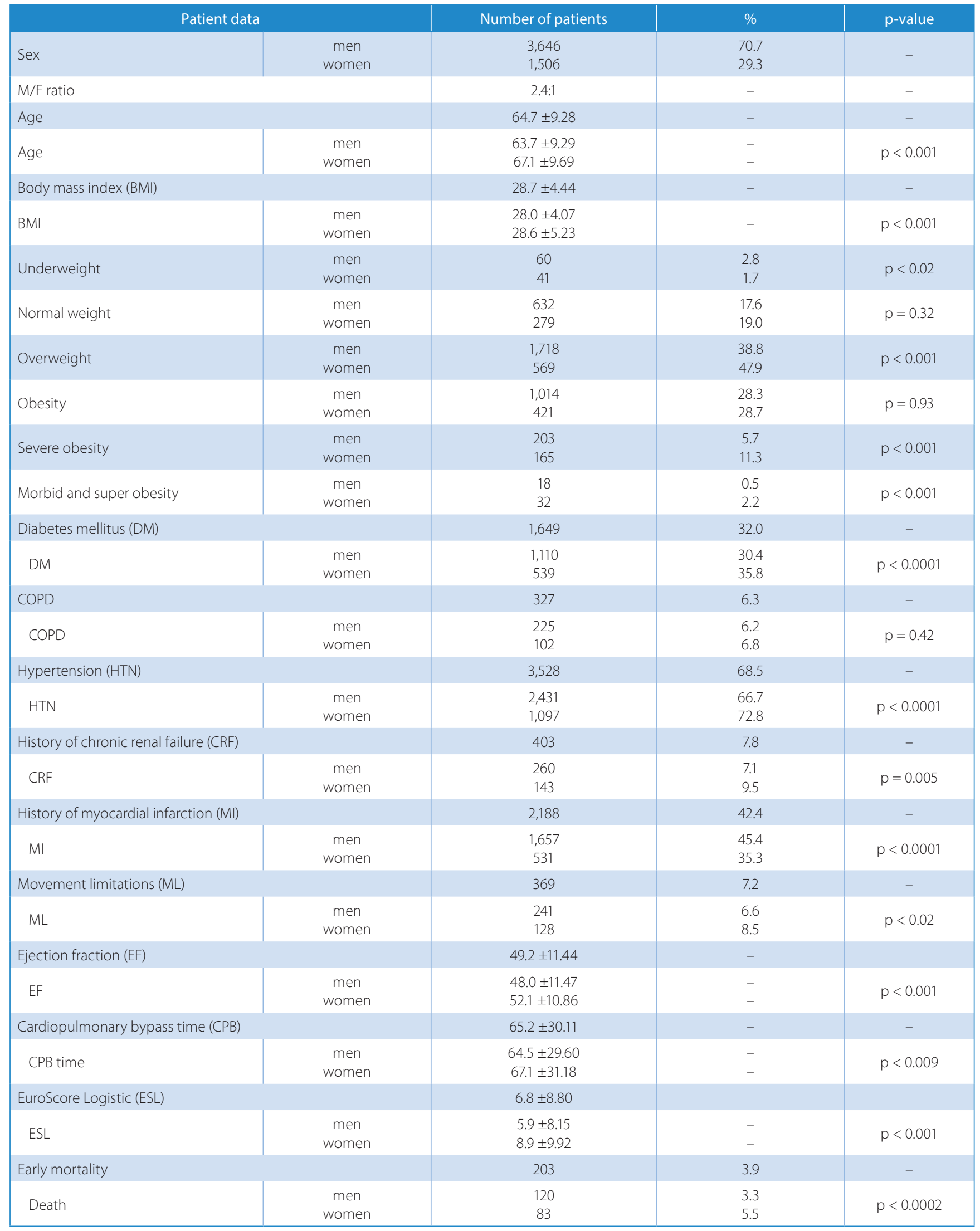

COPD - chronic obstructive pulmonary disease; NYHA - New York Heart Association; CCS - Canadian Cardiovascular Society. 
Table 2. Type of procedures performed by sternotomy on patients operated on in years 2010-2014

\begin{tabular}{|c|c|c|c|c|}
\hline Type of procedure & $\begin{array}{l}\text { Isolated } \\
\text { procedures }\end{array}$ & $\begin{array}{l}\text { Procedures } \\
\text { combined } \\
\text { with } C A B G\end{array}$ & In total & $\%$ \\
\hline $\begin{array}{l}\text { Aortic aneurysm } \\
\text { repair* }\end{array}$ & 287 & 85 & 372 & 7.2 \\
\hline $\begin{array}{l}\text { Aortic valve and mitral } \\
\text { valve procedures }\end{array}$ & 64 & 45 & 109 & 2.1 \\
\hline $\begin{array}{l}\text { Aortic valve } \\
\text { procedures }\end{array}$ & 304 & 354 & 658 & 12.8 \\
\hline $\begin{array}{l}\text { Mitral valve } \\
\text { procedures }\end{array}$ & 198 & $317^{* *}$ & 515 & 10.0 \\
\hline $\begin{array}{l}\text { Isolated tricuspid } \\
\text { valve procedures }\end{array}$ & 24 & 21 & 45 & 1.0 \\
\hline $\begin{array}{l}\text { Other procedures } \\
\text { in } \mathrm{CPB}\end{array}$ & 26 & 12 & 38 & 0.7 \\
\hline CABG & 2,964 & $-{ }^{* * * *}$ & 2,964 & 57.5 \\
\hline OPCAB & 424 & - & 424 & 8.2 \\
\hline $\begin{array}{l}\text { Other off-pump } \\
\text { procedures }\end{array}$ & 27 & - & 27 & 0.5 \\
\hline In total & 4,318 & 834 & 5,152 & 100.0 \\
\hline
\end{tabular}

CPB - cardiopulmonary bypass; CABG - coronary artery bypass grafts $\mathrm{OPCAB}$ - off pump coronary artery bypass; * Valve procedures were omitted if they were performed together with aortic aneurysm repair; ** 1 patient from the isolated procedures group was included in the CABG group, because his left ITA was harvested (but not grafted); ${ }^{* * *}$ Tricuspid valve procedures were omitted if they were performed together with aortic or mitral valve procedures; ${ }^{* * *} 833$ CABG procedures were not included here, as they were performed with other operations listed above

Among 424 patients who had off-pump surgery, one ITA was used in 234 (55.2\%) patients. In 3 patients, however, the ITA was not suitable for grafting. Both ITAs were harvested in 184 patients (43.4\%), although in one case a damaged ITA was not used. Six (1.4\%) patients received a planned graft from the saphenous vein. The data is presented in Table 3.

Sternal dehiscence was found in 45 (0.9\%) of the patients undergoing surgery by median sternotomy. The onset of dehiscence was calculated as the difference between the date of the first surgery and the date of the first sternal reconstruction procedure. Enlarging the wound opening and/or applying VAC dressing were not counted as reconstruction procedures. Early dehiscence up to 30 days from surgery developed in 38 (84.4\%) patients, delayed dehiscence in seven (15.6\%) patients. Six patients had previously undergone a revision of the operative wound (one of the patients twice) due to bleeding (4 patients) and/or thrombus that pressed on the right atrium (3 patients).

The partial reconstructions, performed 45 times in 33 patients, mostly entailed pulling and tightening the loose wire loops due to perceived mobility of the separated sternum and, in some cases, adding wire loops (1-2) to the lower part of the sternum body. If a patient developed full dehiscence, complete sternal osteosynthesis was needed, and this was performed 25 times in 22 patients. In total, 70 different types of reconstruction were conducted.

A partial reconstruction only was required in 23 patients. A single reconstruction was sufficient in 19 patients, whereas 2 were needed in 4 patients (27 procedures, in total). Complete sternal osteosynthesis was required in 22 patients. In 17 patients, the Robicsek closure (10 patients), the standard technique (5 patients), the Martinez closure (1 patient), and the standard technique with Kryptonite reinforcement (1 patient) were used. In 12 patients there was a single procedure, whereas 5 complete reconstructions were followed by 11 partial procedures.

In 4 patients, first reconstructions were partial, followed by the Robicsek closure (2 patients), the standard technique (1 patient) and the standard technique with Kryptonite reinforcement (1 patient). In total, 6 partial reconstructions were performed in this group. One patient had 1 partial and 4 complete procedures of sternum closure ( 2 with the standard method, 1 with the Robicsek closure and 1 with steel plates used to stabilize the chest due to destruction of the sternum).

Furthermore, 29 patients required treatment with VAC therapy. Two hundred and thirty-seven VAC kits were used in the early dehiscence group, 47 in the late dehiscence group (284 in total). The data is presented in Table 4.

Concomitant bacterial wound infection was diagnosed in 26 of 45 (57.8\%) dehiscence cases. In the rest

Table 3. Type of revascularisation procedures performed on patients operated on in years 2010-2014

\begin{tabular}{|c|c|c|c|c|}
\hline Category & CABG & OPCAB & In total & $p$-value \\
\hline Number of used (harvested) single ITAs & $\begin{array}{c}3,280 \\
(86.4 \%)\end{array}$ & $\begin{array}{c}234 \\
(55.2 \%)\end{array}$ & $\begin{array}{c}3,514 \\
(83.2 \%)\end{array}$ & $p<0.00001$ \\
\hline Number of used (harvested) bilateral ITAs & $\begin{array}{c}334 \\
(8.8 \%)\end{array}$ & $\begin{array}{c}184 \\
(43.4 \%)\end{array}$ & $\begin{array}{c}518 \\
(12.3 \%)\end{array}$ & $p<0.00001$ \\
\hline Number of revascularizations without using an ITA & $\begin{array}{c}184 \\
(4.8 \%)\end{array}$ & $\begin{array}{c}6 \\
(1.4 \%)\end{array}$ & $\begin{array}{c}190 \\
(4.5 \%)\end{array}$ & $p<0.01$ \\
\hline Total number of patients undergoing surgery & $\begin{array}{c}3,798 \\
(100.0 \%)\end{array}$ & $\begin{array}{c}424 \\
(100.0 \%)\end{array}$ & $\begin{array}{c}4,222 \\
(100.0 \%)\end{array}$ & - \\
\hline Mean number of bypass grafts per patient & $3.02 \pm 0.95$ & $2.27 \pm 0.68$ & $2.95 \pm 0.95$ & $p<0.001$ \\
\hline Mean number of arterial grafts per patient & $1.19 \pm 0.52$ & $1.75 \pm 0.78$ & $1.24 \pm 0.58$ & $p<0.001$ \\
\hline
\end{tabular}

CABG - coronary artery bypass grafts; OPCAB - off pump coronary artery bypass; ITA - internal thoracic artery. 
Table 4. Primary procedures and methods of treatment patients after early and late dehiscence of sternum

\begin{tabular}{|c|c|c|}
\hline Type of procedure & $\begin{array}{c}\text { Early } \\
\text { dehiscence }\end{array}$ & $\begin{array}{l}\text { Late } \\
\text { dehiscence }\end{array}$ \\
\hline $\begin{array}{l}\text { Number of patients with sternal } \\
\text { dehiscence }\end{array}$ & $\begin{array}{c}38 \\
84.4 \%\end{array}$ & $\begin{array}{c}7 \\
15.6 \%\end{array}$ \\
\hline $\begin{array}{l}\text { Type of primary procedure: } \\
\text { Aortic aneurysm and/or heart valve } \\
\text { procedure + CABG } \\
\text { CABG } \\
\text { OPCAB } \\
\text { Aortic aneurysm/heart valve } \\
\text { procedure without CABG }\end{array}$ & $\begin{array}{c}12 \\
23 \\
2 \\
1\end{array}$ & $\begin{array}{l}- \\
7 \\
- \\
-\end{array}$ \\
\hline $\begin{array}{l}\text { Time between surgery and sternal } \\
\text { dehiscence [days] }\end{array}$ & $\begin{array}{c}5-30 \\
17.5 \pm 7.1\end{array}$ & $\begin{array}{l}36-125 \\
66.6 \pm 9.9\end{array}$ \\
\hline $\begin{array}{l}\text { Postoperative re-explorations before } \\
\text { sternal dehiscence }\end{array}$ & 4 & $2(3)$ \\
\hline $\begin{array}{l}\text { Procedures due to partial dehiscence } \\
\text { or instability of the sternum. }\end{array}$ & 40 & 5 \\
\hline Full sternal closures & 22 & 3 \\
\hline $\begin{array}{l}\text { Number of patients who received VAC } \\
\text { treatment }\end{array}$ & 27 & 2 \\
\hline Number of VAC kits used & $\begin{array}{c}2-29 \\
9.63 \pm 6.98\end{array}$ & $\begin{array}{c}7-17 \\
12 \pm 7.01\end{array}$ \\
\hline
\end{tabular}

CPB - cardiopulmonary bypass; CABG - coronary artery bypass grafts; $O P C A B$ - off pump coronary artery bypass; VAC - vacuum-assisted closure.

of the patients, cultures from the sternal wound were negative. Lysogenic conversion of 3-4 bacteria in the wound was observed in isolated cases, conversion of 2 bacteria was observed in 10 patients. One type of bacteria dominated in the remaining 14 cases. Half of the cultured strains were Gram-positive bacteria (21), the other half (20) were Gram-negative. Details for the bacterial strains are shown in Table 5.

Table 5. List bacterial strains cultured from the wound of sternum in patients after dehiscence

\begin{tabular}{|l|c|c|}
\hline \multicolumn{1}{|c|}{ Bacteria } & Gram stain & Number of cases \\
\hline Enterococcus faecalis & G+ & 6 \\
\hline Enterococcus faecium & G+ & 5 \\
\hline Staphylococcus epidermidis & G+ & 5 \\
\hline Staphylococcus aureus & G+ & 4 \\
\hline Peptoniphilus asaccharolyticus & G+ & 1 \\
\hline Enterobacter cloacae & G- & 5 \\
\hline Pseudomonas aeruginosa & G- & 4 \\
\hline Escherichia coli & G- & 2 \\
\hline Klebsiella pneumoniae & G- & 2 \\
\hline Morganella morganii & G- & 2 \\
\hline Serratia marcescens & G- & 2 \\
\hline Heamophilus influenzae & G- & 1 \\
\hline Proteus mirabilis & G- & 1 \\
\hline Stenotrophomonas maltophilia & G- & 1 \\
\hline In total & G+l- & 41 \\
\hline
\end{tabular}

\section{Results}

Sternal dehiscence occurred about 1.7 times more often in men than in women ( $\mathrm{M}: \mathrm{F}=4: 1$ in the dehiscence group; 2.4:1 in patients without dehiscence), but the differences were not statistically significant. Yet, it should be remembered that both groups differed in terms of age. Patients in the dehiscence group were significantly older, although when adjusted for sex it may be noted that the differences were significant only in men, while the mean age of women was similar in both groups. Obesity dominated in the dehiscence group, whereas overweight was prevalent among patients without this complication. This translated into significant differences in mean BMI values between both groups $-30.2 \pm 4.51$ vs $28.2 \pm 4.45$. The disparities remained significant when the groups were analyzed by sex. Diabetes was the only condition among concomitant and previous diseases found significantly more often in patients with sternal dehiscence. Differences were also statistically significant with regard to COPD, but after incorporating sex differences they were only significant in men. No statistically detectable differences were found for hypertension, renal failure, previous myocardial infarction, poor mobility, NYHA (New York Heart Association) class IV, or stage IV of CCS (Canadian Cardiovascular Society). The mean EF values and $\mathrm{CPB}$ duration also did not differ significantly between the 2 groups. We found, however, that the risk of dehiscence doubled in patients who required a redo procedure due to severe hemodynamic instability, ischemia, bleeding, or compression of the heart by thrombus $(5.2 \%$ vs $13.3 \%$, $\mathrm{p}<0.035)$.

There were also no statistically significant differences in predicted (using the EuroScore Logistic index) and actual early mortality rate. In the sternal dehiscence group, actual mortality was nearly the same as the predicted rate. In the group without dehiscence, actual mortality was about half the predicted mortality. The data is presented in Table 6.

Unilateral or bilateral ITA use during a procedure increased the risk of dehiscence up to $1.1 \%$ and $0.96 \%$, respectively. In the remaining subgroups, the risk of dehiscence was markedly lower and did not exceed $0.5 \%$. The results are presented in Tables 7 and 8.

The only accompanying procedure that was never performed by sternotomy as an independent procedure was RF ablation to treat abnormal conduction pathways in the atria. In total, 230 (4.5\%) such procedures were performed, including 93 ablation procedures combined with isolated CABG in CPB and 4 OPCAB procedures. Only one $(0.4 \%)$ patient from the sternal dehiscence group had a previous accompanying RFA procedure.

In order to analyze the effect of individual risk factors more accurately, we performed logistic regression analysis (LRA) of 16 risk factors: sex, age, BMI, EF, ESL, movement limitations, chronic renal failure, diabetes, COPD, CABG, use of 1 or 2 ITAs, CPB time, NYHA class IV, 
Table 6. Differences in pre- and perioperative data between patients with and without dehiscence after sternotomy

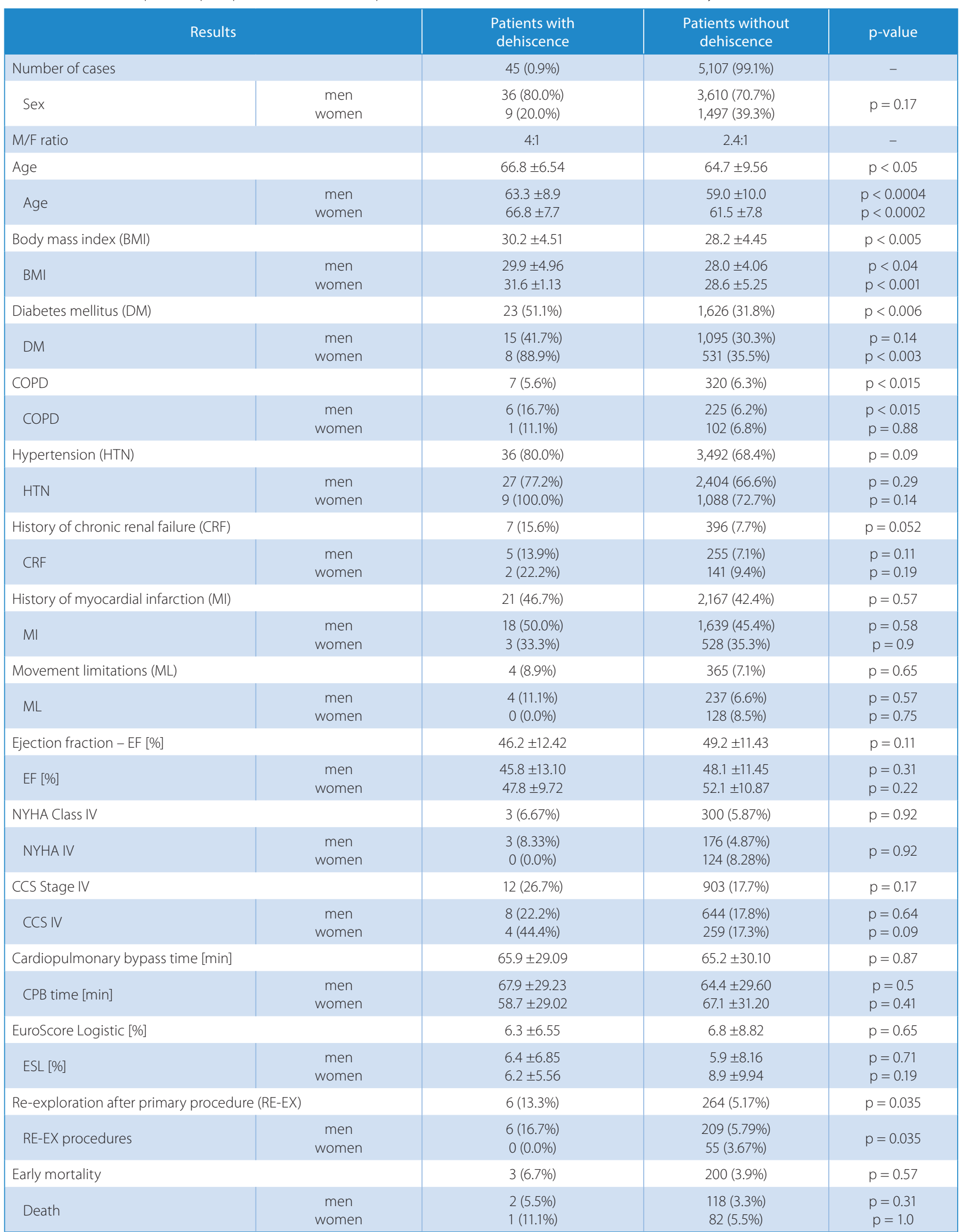

COPD - chronic obstructive pulmonary disease; NYHA - New York Heart Association; CCS - Canadian Cardiovascular Society. 
Table 7. Frequency of dehiscence of sternum depending on isolated coronary or valve procedures and combined operation

\begin{tabular}{|c|c|c|c|c|}
\hline \multicolumn{2}{|c|}{ Type of procedure } & $\begin{array}{c}\text { Sternal } \\
\text { dehiscence }\end{array}$ & $\%$ & $p$-value \\
\hline $\begin{array}{l}\text { Aortic aneurysm } \\
\text { repair* }\end{array}$ & $\begin{array}{c}\text { isolated } \\
\text { with } C A B G\end{array}$ & $\begin{array}{l}1 \\
1\end{array}$ & $\begin{array}{l}0.3 \\
1.2\end{array}$ & $p=0.94$ \\
\hline $\begin{array}{l}\text { Aortic and mitral } \\
\text { valve procedures }\end{array}$ & $\begin{array}{c}\text { isolated } \\
\text { with } C A B G\end{array}$ & $\begin{array}{l}0 \\
1\end{array}$ & $\begin{array}{l}0.0 \\
2.2\end{array}$ & $p=0.86$ \\
\hline $\begin{array}{l}\text { Aortic valve } \\
\text { procedures }\end{array}$ & $\begin{array}{c}\text { isolated } \\
\text { with } C A B G\end{array}$ & $\begin{array}{l}0 \\
4\end{array}$ & $\begin{array}{l}0.0 \\
1.1\end{array}$ & $p=0.17$ \\
\hline $\begin{array}{l}\text { Mitral valve } \\
\text { procedures }\end{array}$ & $\begin{array}{c}\text { isolated } \\
\text { with CABG }\end{array}$ & $\begin{array}{l}1 \\
5\end{array}$ & $\begin{array}{l}0.5 \\
1.6\end{array}$ & $p=0.49$ \\
\hline Other procedures & $\begin{array}{c}\text { isolated } \\
\text { with CABG }\end{array}$ & $\begin{array}{l}0 \\
0\end{array}$ & $\begin{array}{l}0.0 \\
0.0\end{array}$ & - \\
\hline CABG & & 30 & 1.0 & \\
\hline$O P C A B$ & & 2 & 0.5 & \\
\hline In total & & 45 & 0.9 & 5,152 \\
\hline
\end{tabular}

* Valve procedures performed together with aortic aneurysm repair were treated as aneurysm repair procedures.

\section{Discussion}

Sternal dehiscence is a surgical complication which has been reported since 1957, when Julian presented his idea of opening the chest through median sternotomy, ${ }^{7}$ soon accepted as the best method of access to the anterior mediastinum. Unfortunately, mortality reached $50 \%$ when concomitant mediastinitis presented. The introduction of a new method of close wound treatment in 1963, which used irrigation drainage with an antibiotic-containing solution, helped to reduce mortality to $20 \%$ in the most severe cases. ${ }^{8}$ The first studies on the causes of sternal dehiscence appeared at the end of the 1960s due to the rapid increase in the number of CABG procedures and the postoperative complications that had been reported. More than 20 different causes that could directly or indirectly affect the incidence of sternal dehiscence have been identified in the literature. It has been established that this complication develops more frequently in men due to the musculature of the chest,

Table 8. Frequency of dehiscence of sternum depending on using ITAs grafts

\begin{tabular}{|c|c|c|c|c|c|}
\hline \multicolumn{2}{|r|}{ Category } & $\begin{array}{c}\text { Sternal } \\
\text { dehiscence }\end{array}$ & $\begin{array}{c}\text { Without } \\
\text { dehiscence }\end{array}$ & Dehiscence rate & $p$-value \\
\hline 1. & Surgery with 1 (harvested) ITA & 38 & 3,476 & 1.09 & $p<0.005^{1,4}$ \\
\hline 2. & Surgery with 2 (harvested) ITAs & 5 & 513 & 0.96 & $p<0.03^{2,4}$ \\
\hline 3. & Other procedures without using (harvesting) an ITA & 2 & 1,120 & 0.18 & $p<0.005^{3}$ \\
\hline & In total & 45 & 5,107 & 0.87 & - \\
\hline
\end{tabular}

ITA - Internal Thoracic Artery; ${ }^{1} 1$. vs $3 ;{ }^{2} 2$. vs $3 ;{ }^{3} 1 .+2$. vs $3 ;{ }^{4} 1$. vs $2 ., p=0.81$.

stage IV of CCS, and reexploration after primary procedure. The LRA showed that only BMI ( $<<0.015$; OR = 1.08; $95 \% \mathrm{CI}=1.02-1.15)$, diabetes $(\mathrm{p}<0.007 ; \mathrm{OR}=2.34$; $95 \% \mathrm{CI}=1.27-4.31)$, COPD $(\mathrm{p}<0.019 ; \mathrm{OR}=2.68 ; 95 \%$ $\mathrm{CI}=1.18-6.11)$, and re-exploration $(\mathrm{p}<0.012$; $\mathrm{OR}=3.12$; $95 \% \mathrm{CI}=1.29-7.5)$ were independent factors which significantly affected the incidence of sternal dehiscence. Results were confirmed with discriminant analysis. The data is presented in Table 9.

Table 9. Results of logistic regression analysis and discriminant analysis

\begin{tabular}{|l|c|c|c|c|c|}
\multicolumn{1}{|c|}{$\begin{array}{l}\text { Independent } \\
\text { risk factor }\end{array}$} & $\begin{array}{c}\text { Odds ratio } \\
\text { (OR) }\end{array}$ & $-95 \% \mathrm{Cl}$ & $+95 \% \mathrm{Cl}$ & $\mathrm{p}$-value \\
\hline BMI & 2.1 & 1.13 & 3.82 & $\mathrm{p}<0.019$ \\
\hline Diabetes & 2.4 & 1.33 & 4.45 & $\mathrm{p}<0.004$ \\
\hline COPD & 2.7 & 1.2 & 6.24 & $\mathrm{p}<0.016$ \\
\hline Re-exploration & 3.0 & 1.24 & 7.21 & $\mathrm{p}<0.014$ \\
\hline & Discriminant analysis regression analysis & & \\
\hline BMI & - & - & - & $\mathrm{p}<0.013$ \\
\hline Diabetes & - & - & - & $\mathrm{p}<0.002$ \\
\hline COPD & - & - & - & $\mathrm{p}<0.01$ \\
\hline Re-exploration & - & - & - & $\mathrm{p}<0.009$ \\
\hline
\end{tabular}

BMI - body mass index; COPD - chronic obstructive pulmonary disease. but also in women with large breasts and patients with diabetes, patients who are overweight, patients who regularly take steroids, patients receiving immunosuppressive treatment, patients who smoke tobacco, and patients with COPD. Advanced age was also identified as another factor increasing the risk of sternal dehiscence. . $^{2,9,10}$

The technique of proper incision has been stressed as an important perioperative factor since the beginnings of median sternotomy as a surgical procedure. ${ }^{11,12}$ A serious deviation from the symmetry axis of the incision may often result in complicated healing. Mistakes in sternal closure may have a similar effect. ${ }^{4,12}$ Moreover, such factors as time of the operation and exposition of the mediastinum, use of hypothermia, cardiopulmonary bypass, increased blood transfusions, reoperations due to bleeding, and most importantly - using 1, and especially 2 internal thoracic arteries as conduits during surgery were indicated as having an impact, although bilateral ITA use is sometimes challenged in the literature. ${ }^{13-17}$ Postoperative factors that may increase the risk of sternal dehiscence include chest compression during resuscitation, intensive cough among tobacco smokers and patients with COPD, but also intake of specific medicines. ${ }^{18,19}$ In addition, other lung complications that result in strong cough, prolonged intubation and mechanical ventilation may increase the risk of sternal dehiscence. The most serious complication that 
often accompanies sternal dehiscence is an infection of the wound, soft tissues, sternum and mediastinum. ${ }^{14-16,20}$

Prevention of sternal dehiscence is mostly accomplished by eliminating all controllable factors, for example, discontinuation of smoking at least 1 month before surgery and reduction of body mass. Using proper techniques of chest opening and closure is also of vital importance. ${ }^{1,21-29}$ Reoperation due to bleeding or other causes is also a risk factor confirmed in clinical trials. ${ }^{26}$

Infection of the operative wound and sternal dehiscence are 2 closely associated complications, although it is rarely possible to determine which one causes the other. Therefore, appropriate aseptic and antiseptic procedures can have a major impact on the incidence of these complications. ${ }^{20,21}$ In patients with diabetes, it is crucial to maintain glycemic control with insulin infusions in the early postoperative period and appropriately titrated doses in later phases of treatment. ${ }^{10,29}$ Early weaning from mechanical ventilation and rehabilitation from the moment of awakening after surgery contribute to reducing the rate of respiratory complications and consequently to decreasing sternal dehiscence rates. ${ }^{30}$

In 2009, we conducted a similar analysis that covered patients undergoing surgery between 1990 and 2009. We observed at that time that sternal dehiscence was much more frequent among men. Furthermore, patients with sternal dehiscence were significantly older and had a higher BMI. Diabetes and COPD were significantly more frequent in the dehiscence group. ${ }^{5}$ Similar results were obtained in the current study. In comparison to the previous study period, the patients are older and have a higher BMI. The incidence of diabetes and COPD, factors associated with age, has also increased significantly. Moreover, we monitored the impact of other factors that had not been analyzed before, such as concomitant hypertension, renal failure, previous myocardial infarction, and movement limitations, but we did not find any influence on the incidence of the observed cases of sternal dehiscence. In contrast to the previous study, although men dominated in the dehiscence group, the differences attributed to sex lost their statistical significance.

The largest differences pertain to the association between using internal thoracic arteries and postoperative sternal dehiscence. The results of both studies show that harvesting thoracic arteries significantly increased the risk of postoperative dehiscence. However, using our strengthened method of sternum closure reduced that risk by half ( $2.1 \%$ vs $1.1 \%)$. In the previous study, use of both thoracic arteries increased the risk of dehiscence to $4.6 \%$. In the current study using 1 or 2 thoracic arteries did not have any influence on the risk (1.1\% vs $1.0 \%)$. The risk of dehiscence after operations without revascularization of the myocardium fell 14 times in comparison to the previous study - from $1.4 \%$ to $0.1 \%$.

The discriminant analysis of the influence of risk factors on sternal dehiscence performed during previous studies demonstrated the significance of 3 independent risk factors: age, sex and BMI. ${ }^{5}$

In the present study, an LRA was performed. Diabetes, COPD, BMI and re-exploration were identified as independent risk factors. These results were confirmed by DA.

Certainly, it may be argued that the current and previous study group are too different from each other to allow a comparison. However, 2 opposing processes need to be taken into consideration. On one hand, there are the growing risks due to ongoing trends in modern societies such as population ageing, an increasing rate of lifestyle diseases such as diabetes and obesity, and an intensification of unfavorable changes in the surrounding environment - a rising number of antibacteria-resistant bacteria. On the other hand, the operative techniques and methods of postoperative patient management are improving, aseptic and antiseptic techniques in the operative field have been enhanced, and the conditions of hospital stay have been ameliorated. All of the above processes took place gradually, in contrast to the modification of sternal closure, which happened at the beginning of the 5-year study period. Though the results may be referred to 1 specific cardiac surgery center, we believe that some general suggestions may be inferred.

\section{Conclusions}

Introducing a more durable sternum stabilization method with $8+$ loops helped to improve conditions for bone union and reduced the risk of dehiscence. Therefore, we suggest that centers which still use 6-loop sternal closure should consider shifting to a stronger technique.

\section{References}

1. Almdahl SM, Halvorsen P, Veel T, Rynning SE. Avoidance of noninfectious sternal dehiscence: Figure-of- 8 wiring is superior to straight wire closure. Scand Cardiovasc J. 2013;47(4):247-250.

2. Losanoff JE, Richman BW, Jones JW. Disruption and infection of median sternotomy: A comprehensive review. Eur J Cardiothorac Surg. 2002;21(5):831-839.

3. Narang S, Banerjee A, Satsangi DK, Geelani MA. Sternal weave in highrisk patients to prevent noninfective sternal dehiscence. Asian Cardiovasc Thorac Ann. 2009;17(2):167-170.

4. Robicsek F, Fokin A, Cook J, Bhatia D. Sternal instability after midline sternotomy. Thorac Cardiovasc Surg. 2000;48(1):1-8.

5. Listewnik M, Kazimierczak A, Mokrzycki K. Powikłania w kardiochirurgii: rozejścia mostka po pośrodkowej sternotomii. Analiza wyników 14,171 operacji kardiochirurgicznych wykonanych w latach 19902009. Pomeranian J Life Sci. 2015;61(4):383-388.

6. Listewnik MJ, Sielicki P, Mokrzycki K, Biskupski A, Brykczyński M. The use of vacuum-assisted closure in purulent complications and difficult-to-heal wounds in cardiac surgery. Adv Clin Exp Med. 2015; 24(4):643-650.

7. Julian OC, Lopez-Belio M, Dye WS, Javid H, Grove WJ. The median sternal incision in intracardiac surgery with extracorporeal circulation: A general evaluation of its use in heart surgery. Surgery. 1957;42(4):753-761.

8. Shumacker HB, Mandelbaum I. Continuous antibiotic irrigation in the treatment of infection. Arch Surg. 1963;86(3):384-387.

9. Milano CA, Kesler K, Archibald N, Sexton DJ, Jones RH. Mediastinitis after coronary artery bypass graft surgery. Risk factors and longterm survival. Circulation. 1995;92(8):2245-2251. 
10. Zalewska-Adamiec M, Bachórzewska-Gajewska H, Tomaszuk-Kazberuk $A$, et al. Wpływ otyłości na rokowanie i ryzyko powikłań u pacjentów z chorobą pnia lewej tętnicy wieńcowej leczonych kardiochirurgicznie. Pol Przegl Kardiol. 2012;14(1):29-36.

11. Harjula A, Jarvinen A. Postoperative median sternotomy dehiscence. Scand J Thorac Cardiovasc Surg. 1983;17(3):277-281.

12. Shafir R, Weiss J, Herman O, Cohen N, Stern D, Igra Y. Faulty sternotomy and complications following median sternotomy. J Thorac Cardiovasc Surg. 1988;96(2):310-313.

13. Bitner M, Jaszewski R. Rozejścia mostka po operacjach w krążeniu pozaustrojowym w umiarkowanej hipotermii (lata 19871994) i w normotermii ogólnej (lata 1995-2000). Clin Exp Med Lett. 2005;46(3):47-50.

14. Gualis J, Flórez S, Tamayo E, Alvarez FJ, Castrodeza J, Castaño M. Risk factors for mediastinitis and endocarditis after cardiac surgery. Asian Cardiovasc Thorac Ann. 2009;17(6):612-616.

15. Wouters R, Wellens F, Vanermen H, De Geest R, Degrieck I, De Meerleer $F$. Sternitis and mediastinitis after coronary artery bypass grafting. Analysis of risk factors. Tex Heart Inst J. 1994;21(3):183-188.

16. Lemaignen A, Birgand G, Ghodhbane W, et al. Sternal wound infection after cardiac surgery: Incidence and risk factors according to clinical presentation. Clin Microbiol Infect. 2015;21:674.e11-674.e18.

17. Kalush SL, Cherukuri RB, Teller D, Watson C, Murphy B, Shaheen S. Bilateral mammary artery bypass and sternal dehiscence. A favorable outcome. Am Surg. 1990;56(8):487-493.

18. Vymazal T, Horácek M, Durpekt R, Hladíková M, Cvachovec K. Is allogeneic blood transfusion a risk factor for sternal dehiscence following cardiac surgery? A prospective observational study. Int Heart J. 2009;50(5):601-607.

19. Abid Q, Podila SR, Kendall S. Sternal dehiscence after cardiac surgery and ACE type I inhibition. Eur J Cardiothorac Surg. 2001;20(1):203-204.
20. El Oakley RM, Wright JE. Postoperative mediastinitis: Classification and management. Ann Thorac Surg. 1996;61(3):1030-1036.

21. Bitkover CY, Gardlund B. Mediastinitis after cardiovascular operations: A case-control study of risk factors. Ann Thorac Surg. 1998;65(1):36-40.

22. Aykut K, Celik B, Acıkel U. Figure-of-eight versus prophylactic sternal weave closure of median sternotomy in diabetic obese patients undergoing coronary artery bypass grafting. Ann Thorac Surg. 2011; 92(2):638-641.

23. Levin LS, Miller AS, Gajjar AH, et al. An innovative approach for sternal closure. Ann Thorac Surg. 2010;89(6):1995-1999.

24. Okutan $\mathrm{H}$, Tenekeci $\mathrm{C}$, Kutsal A. The reinforced sternal closure system is reliable to use in elderly patients. J Card Surg. 2005;20(3):271-273.

25. Schimmer C, Reents W, Elert O. Primary closure of median sternotomy: A survey of all German surgical heart centers and a review of theliterature concerning sternal closure technique. Thorac Cardiovasc Surg. 2006;54(6):408-413.

26. Schimmer C, Reents W, Berneder S, et al. Prevention of sternal dehiscence and infection in high-risk patients: A prospective randomized multicenter trial. Ann Thorac Surg. 2008;86(6):1897-1904.

27. Totaro $\mathrm{P}$, Lorusso R, Zogno M. Reinforced sternal closures for prevention of sternal dehiscence in high risk patients. J Cardiovasc Surg (Torino). 2001;42(5):601-603.

28. Bottio T, Rizzoli G, Vida V, Casarotto D, Gerosa G. Double crisscross sternal wiring and chest wound infections: A prospective randomized study. J Thorac Cardiovasc Surg. 2003;126(5):1352-1356.

29. Furnary AP, Gao G, Grunkemeier GL, et al. Continuous insulin infusion reduces mortality in patients with diabetes undergoing coronary artery bypass grafting. J Thorac Cardiovasc Surg. 2003;125(5): 1007-1021.

30. Pouwels S, Hageman D, Gommans LNM, et al. Preoperative exercise therapy in surgical care: A scoping review. J Clin Anesth. 2016;33(9): 476-490. 